damage, those who are mentally handicapped for other reasons, and those with dementia or other "incurable" chronic disorders)?

We seem to be progressing down the road of accepting involuntary euthanasia before voluntary euthanasia has been accepted legally. It is unlikely that starvation would be regarded as an acceptable way of assisting dying in voluntary euthanasia, so should we even consider this method for involuntary euthanasia?

\section{Conclusion}

I have asked questions to which I have no answers. The factors influencing them are rarely clinical but depend much more on the attitude of society to the care of disabled people and to social, legal, emotional, political, cultural, religious, and economic forces.
Irrespective of whether it is legal to withhold food from patients in the persistent vegetative state, these problems will continue to face physicians responsible for the long term care of such severely disabled people. Patients and their families may now have to be reassured that the withholding of food will not be automatic. Before such actions are considered it is essential that a full rehabilitation programme should be offered to patients in the early stages of the persistent vegetative state to give them the optimal chance of recovery. And we should be absolutely certain that our diagnosis is correct.

1 Andrews K. Recovery of patients after four months or more in the persistent vegetative state. $B M \mathcal{F}$ 1993;306:1597-600

(Accepted 27 April 1993)

\title{
Patients in the persistent vegetative state: a response to Dr Andrews
}

\section{Raanan Gillon}

The central moral objective of medicine-adhered to by doctors and health care workers since Hippocratic times - is to produce net medical benefit for the patient with as little harm as possible. Today we may add to that Hippocratic objective the moral qualifications that we should pursue it in a way that respects people's deliberated choices for themselves and that is just or fair to others (whether in the context of distribution of scarce resources, respect for people's rights, or respect for morally acceptable laws). This moral frameworka sort of medico-moral mission statement-is consistent with the formal quartet of moral principles introduced to medical ethics by Beauchamp and Childress, which I discuss elsewhere, ${ }^{2}$ and is useful in analysing the various ethical questions posed by Andrews in his two papers in this issue of the $B M \mathcal{F} .^{34}$

\section{Deciding what is net medical benefit}

There are those who believe that preservation of life-any sort of life-is a benefit and worth striving for. For them even maintaining the life of a patient in the persistent vegetative state (when the patient is reliably believed to be in a state of permanent unconsciousness) is a medical benefit worth striving for. Such people argued that Tony Bland-an indisputable example of a patient in the persistent vegetative state, which was reliably believed to be permanent-should have been kept alive, opposing the recommendations of his parents and of his consultant and medical team. Others-I suspect a large majority-believe that continuance of life is a morally neutral means to an endgood only if the continuing life is a "good life." For many of us this means a life that, from the person's own perspective, is worth living.

It is important for health care workers and their patients and potential patients (and increasingly their potential purchasers) to know which view they hold. If they are members of the vitalist persuasion, who favour prolonging life regardless of its quality, they should surely make this clear so that those who reject such views may be warned and take appropriate avoiding action. For my own part, and to declare my own bias, I detest the prospect of being kept alive in any severely disabled state in which I would no longer be able to make deliberated decisions for myself unless there was reason to believe that I had a good chance (preferably better than one in two and certainly better than one in
10) of recovering my ability to be an autonomous agent.

This is of course a major dilemma for members of the medical profession who are of the vitalist persuasionthey presumably feel bad and wrong in "letting go" any human life that could be prolonged. But in trying to resolve their dilemma I believe that they should use the medico-moral framework above and ask themselves whether a patient would, on deliberation have considered the sort of life that seems the probable outcome a life worth living. A variety of evidence may be relevant in answering the question, particularly any advance directives given by the patient. If the patient's views are unavailable the evidence of the patient's proper proxies (usually close relatives or friends) about his or her best interests may be sought. However, even if the proxies believe that preserving the life of the patient in the persistent vegetative state is worthwhile and the patient had given an advance directive to that effect there remains the question of justice. Is the allocation of resources to preserve a life of absent or probably permanently severely impaired consciousness fair or just given that this will deny those resources to all other possible claimants?

Further questions about the treatment of patients in the persistent vegetative state

In his first paper Dr Andrews raises other questions, which I shall consider only briefly-I have addressed some of them more thoroughly elsewhere. ${ }^{5}$

Is artificial hydration and nutrition a medical treatment? Yes, because it is an intervention to prolong life that requires medical skills (imagine leaving to medically unskilled people the nutrition and hydration of long term unconscious people for whom there was a reasonable prospect of good recovery).

Does it matter? Not much. What matters is whether it is care: care requires the intention and prospect of benefit, which takes us back to the question of whether the mere prolongation of life is a benefit, as distinct from a life that the patient considers worth living.

Is the purpose of withdrawing treatment, including hydration and nutrition, to end the life of the patient? It depends on the intention of the decision maker. There is no requirement for such an aim because it is perfectly possible that the purpose of such a decision is only the withdrawal of useless, non-beneficial treatment- 
albeit in the knowledge that this will lead to ${ }^{\kappa}$ the underlying condition causing the patient's death (prolonged unconsciousness of any aetiology is a fatal condition unless treated).

Is the withdrawal of hydration and nutrition part of the cause of the patient's death? Yes, but the moral obligation of the doctor is to provide care, which entails the intention and prospect of benefit, and the mere prolongation of unconscious life is not a benefit. The doctor therefore has no moral obligation to provide hydration and nutrition, and his or her partial role in causing the patient's death is not of moral significance. We all have partial roles in the causation of all sorts of dire events for which we none the less bear no moral responsibility.

Does the decision in the Bland case have adverse implications for disabled people? No more than for anyone else who is unfortunate enough to become permanently unconscious and who requires a share of scarce, and therefore necessarily rationed, medical resources from the community.

Should doctors provide sedation to patients who are conscious and suffering because of withdrawal of otherwise non-beneficial life prolonging treatment? Yes. The fact that we cannot provide medical benefit to cure their condition should in no way prevent us from providing the benefit of reducing or eliminating their suffering.

Are the views of relatives relevant? Well, it depends. A patient who is unable to make autonomous decisions needs a proxy to make decisions on his or her behalf. Close relatives and, increasingly, close friends are recognised as appropriate proxies on the grounds that they are likely to know the person's views and preferences and therefore what is likely to be in the person's best interests. This presumption can always be overridden by a court if there is reason to believe that the proxy is acting against the patient's interests.

\section{The cost of recovery from the persistent vegetative state}

In his second paper Dr Andrews cites cases of recovery from the persistent vegetative state. These include a patient who, after three years in the persistent vegetative state, recovered sufficient consciousness to smile at cartoons, to show pleasure when his wife was present, and to show distress when she was absent. If resources were unlimited, if the patient had not rejected in advance such treatment, and if the patient's proxies and doctor thought that such treatment was in the patient's interests, then the treatment should continue. But resources are severely limited, at least within the NHS. In the NHS we already have to withdraw or withhold life prolonging treatment from patients who would otherwise have longer conscious lives. We withdraw ventilation in certain hopeless cases of respirator dependency; we withdraw dialysis in certain hopeless cases of renal failure; we withdraw or withhold cytotoxic medications in certain hopeless cases of cancer; and we withhold cardiopulmonary resuscitation from patients who are mortally sick or severely and irremediably disabled. In many such cases the patients, were they to be given treatment, would manifest at least as much conscious life as the example of "recovery" after three years of being in a vegetative state cited by Dr Andrews. We withdraw or withhold treatment in such cases because the treatment does not provide more benefit than harm or because, even if it provides net benefit, the patient or his or her proxies reject the treatment or because, even if the patient or proxies believe that the treatment does provide net benefit, the cost to others is too great for its provision to be just or fair.

To feel the force of the latter consideration most of us have only to imagine any clinician in an NHS hospital arguing with colleagues and with hospital finance managers that clearly beneficial life prolonging treatments should be cut back to pay for a patient who, with intensive care and the expenditure of thousands of pounds a year, might, after three years of unconsciousness, regain the ability to smile at cartoons, to be pleased when his wife was present, and to be distressed when she went away.

I write "most of us" while realising that, for some clinicians, my arguments will be morally repellent. For them the saving of human life of any quality and at any cost will always be morally desirable. Let them and their sympathisers seek sufficient support from like minded members of the public to establish privately funded hospices in which, unlike the current hospice movement, patients in the persistent vegetative state are kept alive. Let them carry out prospective research. If its results and quality are sufficiently impressive they will persuade colleagues, the public, the media, and, if necessary, parliament that such treatment should be provided by the NHS. Meanwhile I suspect that most of us believe that the year of such life support recommended by the BMA's working party ${ }^{6}$ and by judgment of the House of Lords in the Bland case ${ }^{7}$ is more than sufficient to reconcile the moral requirements of (possible) benefit to the patient with justice to all.

1 Beauchamp T, Childress J. Principles of biomedical ethics. 3rd ed. Oxford: Oxford University Press, 1989

2 Gillon R. Philosophical medical ethics. Chichester: Wiley, 1985.

3 Andrews K. Patients in the persistent vegetative state: problems in their long term management. BMF 1993:306:1600-2.

4 Andrews K. Recovery of patients after four months or more in the persistent vegetative state. $B M \mathcal{F}$ 1993;306:1597-600.
velows

Gillon R. Persistent vegetative state and medical ethics. St Mary's Gazette 1993;99:17-20. (2 April 1993.)

6 British Medical Association. Discussion paper on treatment of patients in persistent vegetative state-medical ethics committee of the BMA. London: BMA, 1992

7 Withdrawal of medical treatment from hopeless case not unlawful. Times 1993;Feb 5; p 8 (cols 1-7). (Times law report.)

(Accepted 24 May 1993)

\section{Correction}

\section{Thallium poisoning}

As a result of an editorial error figures 1 and 3 in this article by Moore et al (5 June pp 1527-9) were transposed. The legends appeared in the correct orde 